\title{
Fasciotomy closure using negative pressure wound therapy in lower leg compartment syndrome
}

\author{
Krticka $\mathrm{M}^{1}$, Ira $\mathrm{D}^{1}$, Bilik $\mathrm{A}^{1}$, Rotschein $\mathrm{P}^{1}$, Svancara $\mathrm{J}^{2}$ \\ Department of Trauma Surgery, University Hospital, Brno, Czech Republic. milan.krticka@fnbrno.cz
}

\begin{abstract}
BACKGROUND: Fasciotomy wounds can be a major contributor to length of stay for patients as well as a difficult reconstructive challenge.

OBJECTIVES: To evaluate lower leg fasciotomy wound closure outcomes comparing treatment with combined dressing fabric (COM) and negative pressure wound therapy (NPWT) in combination with elastic dynamic ligature (EDL).

METHODS: Retrospective study of 63 patients who underwent lower leg fasciotomy due to injury treated from January 2008 to December 2015 at the Department of Trauma Surgery, University Hospital Brno. Of these fasciotomy wounds 42 received a NPWT treatment in combination with EDL, 21 were treated only with COM. Fasciotomy wounds were closed either with primary suture or in case of persisting oedema and skin retraction the defect was covered with split thickness skin graft.

RESULTS: There was statistically significantly higher rate of primary wound closure using the NPWT versus traditional dressing $(p=0.015)$. Median time to definitive wound closure or skin grafting was shorter in the NPWT group. Number of dressing changes was lower in the NPWT group $(p=0.008)$.

CONCLUSION: NPWT combined with elastic dynamic ligature offers many advantages for fasciotomy wound closure in comparison with traditional techniques (Tab. 5, Fig. 3, Ref. 21). Text in PDF www.elis.sk. KEY WORDS: lower leg, acute compartment syndrome, NPWT, split thickness graft, fasciotomy, wound closure.
\end{abstract}

\section{Introduction}

Acute compartment syndrome (CS) may result from acute trauma to an extremity that is crashed, frequently resulting from complex fracture, arterial injury or vascular occlusion. If CS is left untreated, the condition may result in an intra-compartmental neuromuscular necrosis and functional impairment (1). A diagnosed compartment syndrome needs immediate fasciotomy as an emergency surgical procedure to release the pressure from an affected compartment. However, the fasciotomy wound often represents a problem for surgeon to close it primarily due to the persistent tissue swelling and skin contracture (2).

Standard way how to treat fasciotomy wound (FW) is coverage with wet-to-moist or moist environment dressings. Unfortunately, these dressings are topical and allow the edges to contract away from the incision line. This requires varying methods of stretching the skin for approximation or skin graft for closure.

Split-thickness skin grafting of FW can provide early coverage. However, it produces a donor site pain and results in further

${ }^{1}$ Department of Trauma Surgery, University Hospital, Brno, Czech Republic, and ${ }^{2}$ Institute of Biostatistics and Analyses, Masaryk University, Brno, Czech Republic

Address for correspondence: $\mathrm{M}$. Krticka, $\mathrm{MD}, \mathrm{PhD}$, Department of Trauma Surgery, Jihlavska 20, C-60200 Brno, Czech Republic.

Phone: +420.724.563209 scarring. Skin grafts can also leave a wide, hairless scar over the fasciotomy site that can limit effective muscular function within the compartment (3). Many studies have focused on delayed and dynamic wound closure techniques that can achieve early fasciotomy closure (4). Such techniques avoid creating donor sites but often require prolonged periods of application before wound suture can be achieved. The risk of secondary infection is during this period increased.

Negative pressure wound therapy (NPWT) is a relatively new treatment concept and offers proven method of edema reduction as well as method that provides a moist environment for the wound and reduces its bacterial count (5). There is a limited amount of published material on the use of NPWT associated with traumatic compartment syndrome. Our study demonstrates how primary usage of NPWT could decrease the need for a skin graft to close the FW in comparison with standard way of fasciotomy wounds treatment.

\section{Material and methods}

We retrospectively analyzed the medical records of a consecutive series of adult patients with acute traumatic compartment syndrome of lower leg treated at the University Hospital Brno from January 2008 to December 2015.

The following conditions were specified as inclusion criteria: acute traumatic CS of lower leg; urgent single incision fasciotomy 


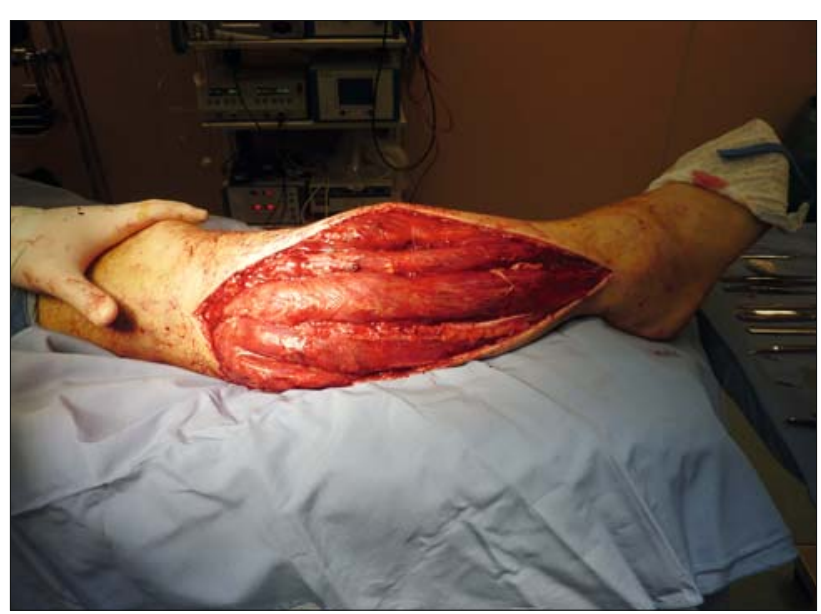

Fig. 1. Single incision fasciotomy of lower leg in patient with acute traumatic compartment syndrome.

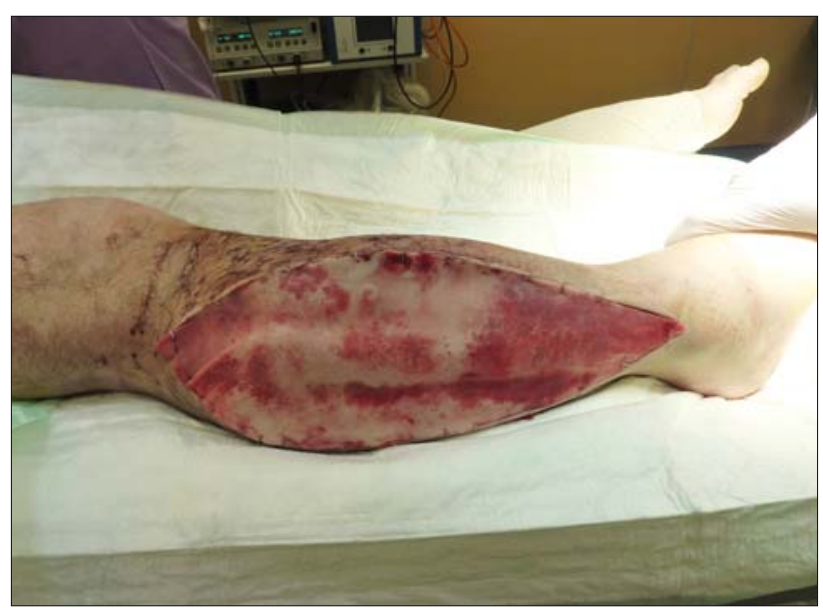

Fig. 2. Fasciotomy wound covered by combined dressing fabric (COM).

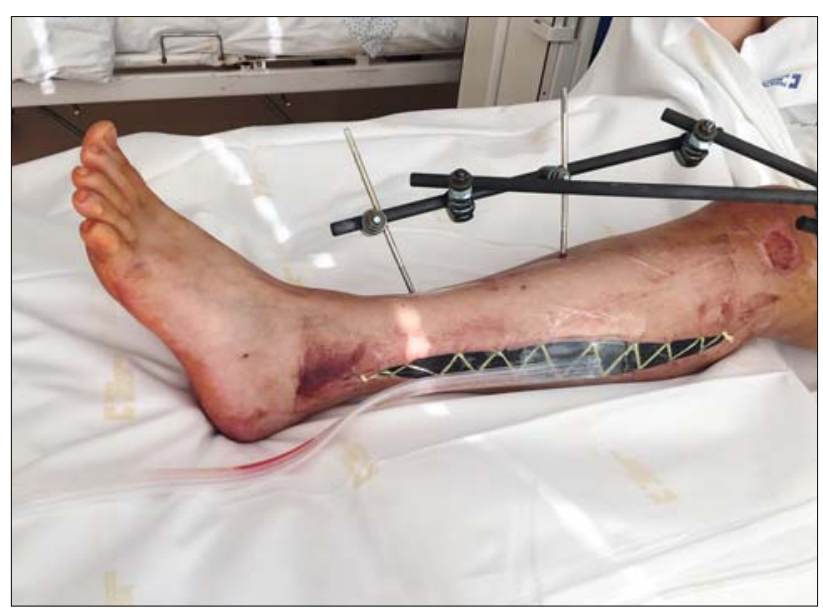

Fig. 3. Fasciotomy wound covered by negative pressure wound therapy in combination with elastic dynamic suture.

(procedure was done up to 2 hours from making a diagnosis (6)), temporary cover of FW by NPWT or by combined dressing fabric $(\mathrm{COM})$ until definitive wound suture or dermo-epidermal (DE) grafting of skin defect; follow-up was a minimum of 1 month after successfully treated FW. Exclusion criteria were following: primary DE grafting of FW straight after fasciotomy; contemporary vascular lesion of injured lower extremity; patient's transfer to other hospital during fasciotomy wound treatment.

Patients were divided into 2 groups. Control group (CG) - patients with standard single incision fasciotomy of lower leg due to acute traumatic compartment syndrome (Fig. 1), COM was applied on FW (Fig. 2) in the operating room, and changed on postoperative day 2 and every $2-3$ days thereafter until fasciotomy wound was step by step sutured or covered by DE graft (in case of impossibility of complete wound suture because of persisting soft tissue swelling or wound edges contraction). Study group (SG) - patients with standard single incision fasciotomy of lower leg because of acute traumatic compartment syndrome, COM was applied in the operating room, and replaced by NPWT in combination with elastic dynamic ligature (EDL) on postoperative day 2 (Fig. 3). EDL was applied according to the method described by Schmidt (7). NPWT was set up on intermittent mode using $125 \mathrm{~mm} \mathrm{Hg}$ of sub- atmospheric pressure. Subsequent surgical dressing changes (with sequential re-suturing) followed after each 3-5 days. Only NPWT with EDL were used to cover FW until it was step by step sutured or covered by DE graft (in case of impossibility of complete wound suture because of continued soft tissue swelling or wound edges contraction).

Data collected for this study included basic demographics, smoking, diabetes history and Injury Severity Score (ISS). We also collected data about injury mechanism, fracture type and associated injuries. Main recorded data were: wound closure type (suture / DE graft), time to definitive wound suture or split thickness skin grafting coverage, number of dressing changes, intra-compartmental muscular necrosis, development of infection, wound dehiscence and fibularis nerve complications. Patient was diagnosed as having an infection when clinical symptoms (purulent secretion from the wound, erythema, fever etc.) were present and laboratory data (elevated CRP, positive bacteriology swab) documented infection.

Variables are described by absolute and relative frequencies and differences between control and tested group were tested by Fisher exact test for binary variables and by Mann-Whitney U test for continuous data. The results were considered statistically significant at the level of alpha $<0.05$ in all applied analyses. Analyses were performed using IBM SPSS Statistics 23.0.0 (IBM Corporation, 2013).

\section{Results}

One hundred and five patients were enrolled into this study, inclusion criteria met 63 patients. Twenty-one patients were enrolled to the control group, whereas 42 patients were enrolled to the study group. Fifty-three males and 10 females entered the study. Patients ranged between 18 and 81 years in age with a mean of 39 years in SG and 43 years in CG. There was no significant difference between the groups regarding age or sex. Forty-nine percent of our patients were smokers with a similar distribution between both groups. Only 6 patients had diabetes, 2 of them were in CG 
Tab. 1. Patient data.

\begin{tabular}{lccc}
\hline Patient data & $\mathrm{CG}(\mathrm{n}=21)$ & $\mathrm{SG}(\mathrm{n}=42)$ & $\mathrm{p}$ \\
\hline Male; $\mathrm{n}(\%)$ & $17(81.0 \%)$ & $36(85.7 \%)$ & 0.917 \\
\cline { 1 - 3 } Female; $\mathrm{n}(\%)$ & $4(19.0 \%)$ & $6(14.3 \%)$ & \\
\hline Smoking; $\mathrm{n}(\%)$ & $9(42.9 \%)$ & $22(52.0 \%)$ & 0.595 \\
\hline Diabetes mellitus; $\mathrm{n}(\%)$ & $2(9.5 \%)$ & $4(9.5 \%)$ & 1.000 \\
\hline $\begin{array}{l}\text { Injury Severity Score; } \\
\text { diameter (range) }\end{array}$ & $21.1(9-57)$ & $20.0(9-57)$ & 0.917 \\
\hline
\end{tabular}

$\mathrm{CG}=$ control group, $\mathrm{SG}=$ study group

and 4 of them in SG. There were also no significant differences between both groups. Injury Severity Scores were similar between the groups with a mean of 21.1 for controls and 20 for study group patients. Patient data are summarized in Table 1.

All patients had injury resulting from high-energy mechanism. The mechanism of injury is presented in Table 2 and there were no significant differences.

Fracture of ipsilateral lower extremity was present in 19 patients in CG and in 37 patients in SG. In some cases, 2 fractures were present in the same patient. 3 patients had dislocation of the knee. Localization and sum of the fractures and knee luxation are presented in Table 3.

The decision to perform fasciotomy was based on suspicion or presence of clinical symptoms of CS in all patients. The timing of fasciotomy with respect to associated extremity injury was variable. In sixty-seven percent of cases $(n=42)$, fasciotomies were performed during the fracture fixation, where findings before operation or in theatre indicated an impending compartment syndrome. Thirty-three percent $(n=21)$ of fasciotomies were performed after fracture fixation. The mean time to fasciotomy following initial traumatic injury was 33 hours ( 35 hours in SG and 31 hours in CG). There were no significant differences between both groups, data are summarized in Table 4.
The median time from single incision fasciotomy to wound closure for CG was 17 days compared with 11 days in TG. The difference between both groups was not statistically significant ( $p$ $=0.136$ ). Mean number of dressing changes in CG was higher (6) compared to SG (3). The difference was statistically significant ( $\mathrm{p}$ $=0.008)$. Forty-eight percent of fasciotomies $(\mathrm{n}=10)$ in CG were covered with DE graft because of impossibility to make a suture with respect to persisting muscle swelling and wound margin retraction, whereas in SG only $17 \%(n=7)$ of fasciotomies were closed by DE graft, remaining fasciotomies were sutured. The difference between both groups was statistically significant $(\mathrm{p}=$ 0.015), data are summarized in Table 4.

Number of infectious complications of fasciotomy wounds was similar in both groups. Wound infection was present in 3 patients $(14.2 \%)$ in CG and in 4 patients $(9.5 \%)$ in SG. All of these patients were successfully treated with antibiotics and standard surgical therapy. Muscle necrosis because swelling and muscle ischemia were present in 6 patients $(28.6 \%)$ from CG and in 3 patients $(7.1 \%)$ from SG. The difference between both groups was statistically significant $(p=0.049)$. Osteomyelitis of fractured bone in lower leg with developed CS was diagnosed in 1 patient, proximal tibial fracture from $\mathrm{CG}$ and in 2 patients with proximal tibial and tibial shaft fracture from SG. Data with infection complications are presented in Table 5. All patients with osteomyelitis were treated with prolong antibiotic therapy and with repetitive surgical debridement.

\section{Discussion}

Acute CS is a severe medical condition. The most effective therapy is an early diagnosis and early treatment. Diagnosis of the CS should be based on clinical symptoms and measuring the intra-compartmental pressure. Various techniques and devices for

Tab. 2. Mechanism of injury.

\begin{tabular}{|c|c|c|c|c|}
\hline \multirow{2}{*}{ Mechanism of injury } & \multirow{2}{*}{ Total $(n=63)$} & \multicolumn{2}{|c|}{ Group } & \multirow{2}{*}{$\mathrm{p}$} \\
\hline & & $\mathrm{CG}(\mathrm{n}=21)$ & $\mathrm{SG}(\mathrm{n}=42)$ & \\
\hline Motor vehicle crash & $5(7.9 \%)$ & $3(14.3 \%)$ & $2(4.8 \%)$ & 0.323 \\
\hline Pedestrian vs motor vehicle & $12(19.0 \%)$ & $4(19.0 \%)$ & $8(19.0 \%)$ & 0.624 \\
\hline Motorcycle & $13(20.6 \%)$ & $4(19.0 \%)$ & $9(21.4 \%)$ & 1.000 \\
\hline Bicycle & $3(4.8 \%)$ & $1(4.8 \%)$ & $2(4.8 \%)$ & 1.000 \\
\hline Crash & $12(19.0 \%)$ & $4(19.0 \%)$ & $8(19.0 \%)$ & 1.000 \\
\hline Fall & $18(28.6 \%)$ & $5(23.8 \%)$ & $13(31.0 \%)$ & 0.768 \\
\hline
\end{tabular}

$\mathrm{CG}=$ control group, $\mathrm{SG}=$ study group

Tab. 3. Fracture type.

\begin{tabular}{|c|c|c|c|c|}
\hline & \multirow{2}{*}{ Total $(n=63)$} & \multicolumn{2}{|c|}{ Group } & \multirow[t]{2}{*}{$\mathrm{p}$} \\
\hline & & $\mathrm{CG}(\mathrm{n}=21)$ & $\mathrm{SG}(\mathrm{n}=42)$ & \\
\hline Femur & $6(9.5 \%)$ & $2(9.5 \%)$ & $4(9.5 \%)$ & 1.000 \\
\hline Proximal tibia & $17(27.0 \%)$ & $6(28.6 \%)$ & $11(26.2 \%)$ & 1.000 \\
\hline Tibial shaft & $30(47.6 \%)$ & $9(42.9 \%)$ & $21(50.0 \%)$ & 0.789 \\
\hline Pilon & $5(7.9 \%)$ & $2(9.5 \%)$ & $3(7.1 \%)$ & 1.000 \\
\hline Ankles & $1(1.6 \%)$ & $1(4.8 \%)$ & $0(0.0 \%)$ & 0.333 \\
\hline Dislocation of knee & $4(6.3 \%)$ & $1(4.8 \%)$ & $3(7.1 \%)$ & 1.000 \\
\hline
\end{tabular}

$\mathrm{CG}=$ control group, $\mathrm{SG}=$ study group 
Tab. 4. Timing of fasciotomy and type of closure.

\begin{tabular}{|c|c|c|c|c|}
\hline \multirow{2}{*}{ Timing of fasciotomy } & \multirow{2}{*}{ Total $(n=63)$} & \multicolumn{2}{|c|}{ Group } & \multirow{2}{*}{$\mathrm{p}$} \\
\hline & & CG $(n=21)$ & $\mathrm{SG}(\mathrm{n}=42)$ & \\
\hline During FF & $42(66.7 \%)$ & $16(76.2 \%)$ & $26(61.9 \%)$ & 0.396 \\
\hline 12 hours after FF & $4(6.3 \%)$ & $2(9.5 \%)$ & $2(4.8 \%)$ & 0.595 \\
\hline 24 hours after FF & $10(15.9 \%)$ & $3(14.3 \%)$ & $7(16.7 \%)$ & 1.000 \\
\hline 48 hours after FF & $7(11.1 \%)$ & $0(0.0 \%)$ & $7(16.7 \%)$ & 0.053 \\
\hline \multicolumn{5}{|l|}{ Type of FW closure } \\
\hline Suture & $46(73.0 \%)$ & $11(52.4 \%)$ & $35(83.3 \%)$ & \multirow{2}{*}{$0.015^{*}$} \\
\hline$\overline{\text { DE Graft }}$ & $17(27.0 \%)$ & $10(47.6 \%)$ & $7(16.7 \%)$ & \\
\hline
\end{tabular}

$\mathrm{FF}=$ fracture fixation, $\mathrm{DE}=$ dermo-epidermal, $\mathrm{FW}=$ fasciotomy wound, $\mathrm{CG}=$ control group, $\mathrm{SG}=$ study group

Tab. 5. Complications.

\begin{tabular}{|c|c|c|c|c|}
\hline \multirow{2}{*}{ Type of complication } & \multirow{2}{*}{ Total $(n=63)$} & \multicolumn{2}{|c|}{ Group } & \multirow[b]{2}{*}{$\mathrm{p}$} \\
\hline & & $\mathrm{CG}(\mathrm{n}=21)$ & $\mathrm{SG}(\mathrm{n}=42)$ & \\
\hline Wound infection & $7(11.1 \%)$ & $3(14.3 \%)$ & $4(9.5 \%)$ & 0.677 \\
\hline Necrosis of lower leg muscle & $9(14.3 \%)$ & $6(28.6 \%)$ & $3(7.1 \%)$ & $0.049 *$ \\
\hline Osteomyelitis & $3(4.8 \%)$ & $1(4.8 \%)$ & $2(4.8 \%)$ & 1.000 \\
\hline
\end{tabular}

$\mathrm{FW}=$ fasciotomy wound, $\mathrm{CG}=$ control group, $\mathrm{SG}=$ study group

intra-compartment pressure measurement are reported in the literature. Patients who were enrolled to our study did not undergo an intra-compartmental measuring, because we do not standardly use it. The reason for our approach is a generally accepted rule that diagnosis of CS is based on the surgeon's awareness of this complication and appropriate clinical examination (8). Supporting this approach are also the results of a cohort study with more than 200 patients with tibial diaphyseal fractures, where the use of continuous compartment pressure monitoring did not reveal any differences in outcome and time delay from injury to fasciotomy as compared to clinically examined patients (9).

Another study demonstrated that complication rates and late sequels were similar in alert patients with or without continuous compartment pressure monitoring (10). Once the diagnosis of CS is established, the surgical decompressive fasciotomy should be urgently performed. There are various techniques of lower leg fasciotomy, which include single incision fasciotomy with or without fibulectomy and two incision fasciotomy. The single incision fasciotomy is standardly used in our department in this case and we agree with results of study described by Bible et al. who concluded that the results of fasciotomy techniques mentioned above are similar (11). Primary closure of FW is not appropriate and achieving a delayed primary closure is not always possible. This is caused by the presence of oedema, skin retraction and skin edge necrosis. Split-thickness skin grafting is effective but it results in an insensate and cosmetically unappealing wound and is associated with donor site morbidity (12), (13). Serial dressing changes are needed in traditional moist environment until definitive closure is possible, which puts wound at the risk of infection. Primary coverage with NPWT creates a closed environment which protects the wound from outside infection (14), (15).

Combination of NPWT with using a dynamic method for dynamic skin suture of FW (shoelace technique, elastic dynamic ligature) should be very effective with respect to combination gradual mechanical apposition of wound edges advantages of NPWT.
There are currently few studies in the literature that have performed an analysis of the effect of NPWT on FW closure following acute traumatic lower leg CS. None of these studies have compared combination of NPWT and dynamic skin suture technique for fasciotomy wound closure. On the contrary to relative homogeneity of SG and CG in our study (acute injury, lower leg compartment syndrome, urgent single incision fasciotomy) most published articles compared relatively heterogenous study groups referring to fasciotomy site or the cause of compartment syndrome $(16,17,18)$.

Lee et al represented similar concept in patients with necrotizing fasciitis. Authors applied extended NPWT over dermotraction on mean initial open wound area of $658 \mathrm{~cm}^{2}$ and they gained direct closure in 7 out of 8 patients in a mean time of 16 days (19). These data support our hypothesis that the combination of these two techniques is advantageous, but in our study we had different type and size of FW. In other study of Price at al. it was concluded that application of dynamic wound closure as independent method took slightly longer to achieve wound closure than delayed primary closure methods and had much higher re-operation and complication rate. From this point of view and based on our results of statistically significantly lower frequency of dressing changes in NPWT group compared to control group, it supports the idea of combination of these two techniques (16).

Saziye et al. have reported a decreased FW size after application of NPWT (17). Zannis et al in his study concluded that there was statistically significantly higher rate of primary closure using VAC versus traditional wet to dry dressings (18). These data are also corresponding with our results of statistically significantly lower usage of DE grafts in the NPWT group. Kakagia et al in his prospective randomised study comparing VAC therapy and shoelace technique had mean closure time of FW in VAC group 19 days compared to 15 days in shoelace technique and infection rate was $14 \%$ in VAC group (20). In our study the median time to FW closure was 11 days in NPWT group, which is shorter, with infection rate $14.3 \%$ being the same as in Kakagia study. In the 
710-714

literature an experimental model of pig negative effect of NPWT to muscle fiber regeneration is described (21). This fact is not corresponding with our study, where we had statistically significant decrease of lower leg muscle necrosis in NPWT group compared to control group. But in our study necrosis was assessed by visual control and the test of muscle reaction was performed by surgeon during changing of dressing. Also median time (11 days) of application of NPWT in our study group is close to "safe time of 7 days application", while in Wilkin study no differences were found between the control and NPWT group.

In conclusion, our results show that the use of NPWT in combination with elastic dynamic ligature is a safe method of FW treatment and the combination of these two techniques is more advantageous then to use them alone. This combined technique offers many advantages for fasciotomy wound closure in comparison with traditional techniques. Higher rate of complete fasciotomy wound sutures, lower number of dressing changes and shorter time to definitive wound treatment decrease the time of hospitalization stay, allow earlier rehabilitation and lead to increased patient satisfaction.

\section{References}

1. Volkmann R. Die ischaemischen Muskellähmungen und Kontrakturen. Zbl Chir 1881; 8: 801-803.

2. Rorabeck CH. The treatment of compartment syndromes of the leg. J Bone Joint Surg Br 1984; 66 (1): 93-97.

3. Rogers GF, Maclellan RA, Liu AS et al. Extremity fasciotomy wound closure: comparison of skin grafting to staged linear closure. J Plast Reconstr Aesthet Surg 2013; 66: 90-91.

4. Keudell AG, Weaver MJ, Appleton PT et al. Diagnosis and treatment of acute extremity compartment syndrome. Lancet 2015; 386 (10000): 1299-310.

5. Krug E, Berg L, Lee $\mathbf{C}$ et al. Evidence-based recommendations for the use of Negative Pressure Wound Therapy in traumatic wounds and reconstructive surgery: steps towards an international consensus. Injury 2011; (42) S1: S1-S12.

6. Maheshwari R, Taitsman LA, Barei DP. Single-incision fasciotomy for compartmental syndrome of the leg in patients with diaphyseal tibial fractures. J Orthop Trauma 2008; 22 (10): 723-730.

7. Stannard JP, Schmidt AH, Kregor PJ. Surgical treatment of orthopaedic trauma. New York: Thieme, 2011: 44-57.

8. Frink M, Hildebrand F, Krettek Ch, Brand J, Hankemeier S. Compartment Syndrome of the Lower Leg and Foot. Clin Orthop Relat Res 2010; 468 (4): 940-950.
9. Al Dadah OQ, Darrah C, Cooper A, Donell ST, Patel AD. Continuous compartment pressure monitoring vs. clinical monitoring in tibial diaphyseal fractures. Injury 2008; 39: 1204-1209.

10. Harris IA, Kadir A, Donald G. Continuous compartment pressure monitoring for tibia fractures: does it influence outcome? J Trauma 2006; 60: 1330-1335.

11. Bible JE, McClure DJ, Mir HR. Analysis of Single-Incision Versus Dual-Incision Fasciotomy for Tibial Fractures With Acute Compartment Syndrome. J Orthop Trauma 2013; 27 (11): 607-611.

12. Fitzgerald AM, Gaston P, Wilson Y, Quaba A, McQueen MM. Longterm sequelae of fasciotomy wounds. Br J Plast Surg 2000; 53 (8): 690-693.

13. Velmahos GC, Theodorou D, Demetriades D et al. Complications and nonclosure rates of fasciotomy for trauma and related risk factors. World J Surg 1997; 21 (3): 247-253.

14. Krtička M, Ira D, Nekuda V, Mašek M, Švancara J. Effect of Negative Pressure Wound Therapy on Infectious Complications in Grade III Open Fractures. Acta Chir Orthop TraumaČechoslov 2016; 83 (2): 117122.

15. Krass V, Procházka V, Kužma J, Vlachová H, Veselý R. Compartment syndrome in trauma of limbs. Using the vacuum therapy (VAC system) treatment. Úraz chir 2013; 21 (2): 38-43.

16. Price G, Hodgins N, Fogarty B. A comparison of fasciotomy wound closure methods following extremity compartment syndrome at a regional trauma centre. Eur J Plast Surg 2016; 39 (2): 99-106.

17. Saziye K, Mustafa C, Ilker U, Afksendyios K. Comparison of vacuum-assisted closure device and conservative treatment for fasciotomy wound healing in ischaemia-reperfusion syndrome: preliminary results. Int Wound J 2011; 8 (3): 229-236.

18. Zannis $\mathbf{J}$, Angobaldo J, Marks $\mathbf{M}$ et al. Comparison of fasciotomy wound closures using traditional dressing changes and the vacuum-assisted closure device. Ann Plast Surg 2009; 62 (4): 407-409.

19. Lee JY, Jung H, Kwon H, Jung SN. Extended negative pressure wound therapy- assisted dermotraction for the closure of large open fasciotomy wounds in necrotizing fasciitis patients. World J Emerg Surg 2014; 9: 29.

20. Kakagia D, Karadimas EJ, Drosos G, Ververidis A, Trypsiannis G, Verettas D. Wound closure of leg fasciotomy: Comparison of vacuumassisted closure versus shoelace technique. A randomised study. Injury 2014; 45 (5): 890-893.

21. Wilkin G, Khogali S, Garbedian S et al. Negative-Pressure wound therapy after fasciotomy reduces muscle fiber regeneration in a pig model. J Bone Joint Surg Am 2014; 96 (16): 1378-1385.

Received August 10, 2016. Accepted August 30, 2016. 